\title{
Assessment of Reaction Parameters in the Polymeric Carbon Nitride Thermal Synthesis and the Influence in Photocatalytic Hydrogen Production
}

\author{
Dalila S. Monteiro, ${ }^{a}$ Marcus Vinicius S. Silva ${ }^{b}$ and Luciana A. Silva ${ }^{\circledR *, a, c}$ \\ ${ }^{a}$ Instituto de Química, Universidade Federal da Bahia, Campus de Ondina, \\ 40170-290 Salvador-BA, Brazil \\ ${ }^{b}$ Instituto de Física, Universidade Federal da Bahia, Campus de Ondina, \\ 40170-290 Salvador-BA, Brazil \\ ${ }^{c}$ Centro Interdisciplinar de Energia e Ambiente (CIEnAm), Universidade Federal da Bahia, \\ 40170-290 Salvador-BA, Brazil
}

\begin{abstract}
In this work, the reaction parameters for polymeric carbon nitride synthesis by thermal polycondensation were assessed, such as type of precursor, heating rate and time of thermal treatment, in order to obtain crystalline materials with high photocatalytic performance. All synthesized materials were tested as photocatalysts in hydrogen production using ethylenediaminetetraacetic acid (EDTA) as a sacrificial reactant under visible light irradiation $(\lambda \geq$ $420 \mathrm{~nm}$ ). The synthesis condition capable to obtain the material that reached the best performance in photocatalytic hydrogen production was using thiourea as the precursor, due to the band gap narrowing and charge recombination suppression; an intermediate heating rate $\left(5^{\circ} \mathrm{C} \mathrm{min}^{-1}\right)$ and a longer thermal treatment time $(6 \mathrm{~h})$ that yielded a better crystalline solid. The combination of these effects led the S-doped polymeric carbon nitride (SPCN4 sample) to a higher photocatalytic activity, reaching the maximum hydrogen production rate of $214.75 \mu \mathrm{mol} \mathrm{g} \mathrm{g}^{-1} \mathrm{~h}^{-1}$.
\end{abstract}

Keywords: polymeric carbon nitride, S-doped, synthesis parameters, photocatalysis, hydrogen, EDTA

\section{Introduction}

In the last decade, a lot of attention was devoted to study carbon nitride-based materials, nontoxic metal-free photocatalysts that exhibit a great potential for photocatalytic hydrogen evolution. Generically treated as graphitic carbon nitride $\left(\mathrm{g}-\mathrm{C}_{3} \mathrm{~N}_{4}\right)$, a graphitic structure composed only of $\mathrm{C}$ and $\mathrm{N}$ bonds, ${ }^{1}$ actually the polymeric carbon nitride $(\mathrm{PCN})$ is the structure responsible for photocatalytic activity. ${ }^{2}$ The PCN comprises of linear polymer melon that consists of interconnected tri-s-triazines via secondary nitrogen atoms and two main 2D structures: poly(heptazine imide)s that comprises rings of six heptazine units linked by $\mathrm{N}-\mathrm{H}$ bridges and triazinebased graphitic carbon nitride (TGCN) that consists of nitrogen linked triazine units of $\mathrm{sp}^{2}$-hybridized carbon and nitrogen atoms. ${ }^{2}$

Thermal polycondensation of precursors rich in nitrogen is the most widely used method in the synthesis of

*e-mail: las@ufba.br
PCN..$^{1-14}$ In this process the precursors are first condensed to melamine and subsequently converted to tri-s-triazine above $390^{\circ} \mathrm{C}$, while the monomers tri-s-triazine are polymerized above $520^{\circ} \mathrm{C}^{3,4}$ In this way, the thermal treatment of the precursors for obtaining crystalline PCN is carried out at $550^{\circ} \mathrm{C}$ for the most works. However, there is no consensus about the time of thermal treatment, which varies from 4 to $6 \mathrm{~h}$, and the heating rate to reach $550^{\circ} \mathrm{C}$, that varies from 2 to $10^{\circ} \mathrm{C} \mathrm{min}^{-1} .^{5-14}$ In general, the physical chemistry properties of $\mathrm{PCN}$ are related to the reaction parameters used in the synthesis, which will affect the photocatalytic activity of this material. On the other hand, an effective way to improve the photocatalytic efficiency of $\mathrm{PCN}$ is through doping with larger heteroatoms like sulfur, which achieves narrower band gap and lower highest occupied molecular orbital (HOMO) level in the conjugated polymer. ${ }^{15}$ Thus, in this work, we have investigated the influence of synthesis parameters, such as heating rate, time of thermal treatment and the presence of sulfur as heteroatom by using different precursors, urea and thiourea, in the photocatalytic activity of PCN. 
Semiconductor materials obtained from different conditions of synthesis were tested as photocatalysts in hydrogen production using ethylenediaminetetraacetic acid (EDTA) as a sacrificial reactant and platinum as a cocatalyst under visible light irradiation. This complexing agent is widely used in pharmaceutical, textile and paper pulp manufacturing. Although EDTA is not considered toxic, it is an indirect pollutant of water because the capacity of complexation that induces the formation of very stable complexes with toxic metallic ions. Besides, EDTA oxidation potential is around $0.6 \mathrm{~V}$, thermodynamically capable of transferring electrons to the photogenerated holes $(\mathrm{E}=1.6 \mathrm{~V})$ on the PCN surface, ${ }^{15}$ which justifies its use as a sacrificial reactant in photocatalytic hydrogen production.

\section{Experimental}

Polymeric carbon nitride was prepared by thermal synthetic route, using urea (Neon, Brazil) and thiourea (Neon, Brazil) as precursors. Each precursor was ground and placed in a capped crucible coated with aluminum foil. The crucible was heated in a muffle at $550{ }^{\circ} \mathrm{C}$ in atmospheric air, under six different conditions for each precursor as shown in Table 1.

Table 1. Thermal treatment conditions of the different precursor with respective sample codes

\begin{tabular}{lccc}
\hline Sample code & Precursor & $\begin{array}{c}\text { Heating rate / } \\
\left({ }^{\circ} \mathrm{C} \mathrm{min}^{-1}\right)\end{array}$ & $\begin{array}{c}\text { Heating } \\
\text { time }^{\mathrm{a}} / \mathrm{h}\end{array}$ \\
\hline PCN1 & urea & 10 & 4 \\
PCN2 & urea & 10 & 6 \\
PCN3 & urea & 5 & 4 \\
PCN4 & urea & 5 & 6 \\
PCN5 & urea & 2 & 4 \\
PCN6 & urea & 2 & 6 \\
SPCN1 & thiourea & 10 & 4 \\
SPCN2 & thiourea & 10 & 6 \\
SPCN3 & thiourea & 5 & 4 \\
SPCN4 & thiourea & 5 & 6 \\
SPCN5 & thiourea & 2 & 4 \\
SPCN6 & thiourea & 2 & 6 \\
\hline
\end{tabular}

${ }^{a}$ Total time of heat treatment (ramp + hold).

The powders were characterized by X-ray diffraction (Shimadzu XRD6000), using $\mathrm{Cu} \mathrm{K} \alpha$, Ni-filtered radiation, and scanning rate of $2^{\circ} 2 \theta \mathrm{min}^{-1}$, in a $2 \theta$ range of $5-80^{\circ}$, at $35 \mathrm{kV}$ and $15 \mathrm{~mA}$. The average crystallite diameters were calculated from the $\mathrm{X}$-ray line broadening at $2 \theta=27.38^{\circ}$ using the Debye-Scherrer equation. UV-Vis diffuse reflectance spectra were recorded on a spectrometer Thermo Scientific Evolution 600 UV-Vis by using a Praying Mantis ${ }^{\mathrm{TM}}$ accessory and Fourier transform infrared by attenuated total reflection (ATR-FTIR) spectra were recorded on a spectrometer Shimadzu IRAffinity using 32 spectral scans accumulation in the range of 4000 a $400 \mathrm{~cm}^{-1}$ with $4 \mathrm{~cm}^{-1}$ resolution. The Raman spectra were obtained on a Cora 5000X Raman Spectrometer with $1064 \mathrm{~nm}$ laser. All Raman spectra were recorded using 10 spectral scans accumulation and $5 \mathrm{~s}$ exposure time. The Brunauer-Emmett-Teller (BET) surface areas were taken from the treatment of $\mathrm{N}_{2}$ adsorption isotherms determined at $77 \mathrm{~K}$, after vacuum pretreating the samples at $323 \mathrm{~K}$ for $12 \mathrm{~h}$ in a Micromeritics ASAP2020 automated sorptometer. Scanning electron microscopy (SEM) images were taken in JSM-6610LV (JEOL) operated at $20 \mathrm{kV}$ after gold metallization. Sulfur elemental analysis was performed in a TruSpec CNS analyzer (LECO) in which $50 \mathrm{mg}$ of each sample were burned at $1400{ }^{\circ} \mathrm{C}$ in $99.5 \%$ oxygen in triplicate. The photoluminescence measurements were carried out at room temperature with xenon lamp, filtered at $370 \mathrm{~nm}$, as an excitation source in a CVH 100 Thorlab cuvette holder at 90 degrees configuration.

For each photocatalytic test, $100 \mathrm{mg}$ of a given photocatalyst were dispersed in $100 \mathrm{~mL}$ of EDTA disodium (Quimica Moderna, Brazil) solution $\left(0.04 \mathrm{~mol} \mathrm{~L}^{-1}\right)$, with $\mathrm{pH}$ adjusted to 7. Metallic platinum was photodeposited in situ on the photocatalyst surface with addition of 8 wt. $\% \mathrm{H}_{2}\left[\mathrm{PtCl}_{6}\right] .6 \mathrm{H}_{2} \mathrm{O}$ solution (Sigma-Aldrich, USA), corresponding to $0.5 \mathrm{wt} . \%$ Pt. The photocatalytic cell was purged with argon for 30 min to eliminate oxygen gas. A high-pressure $500 \mathrm{~W} \mathrm{Hg-Xe} \mathrm{arc} \mathrm{lamp} \mathrm{(Newport)} \mathrm{was}$ used as the light source for the photocatalytic reactions. The collimated light beam was passed through an IR filter (Newport) cooled by a thermostatic bath (Quimis), a focusing lens and a $420 \mathrm{~nm}$ cutoff filter before reaching the photocatalytic cell, which was air-cooled to maintain the reactor at room temperature. The photocatalytic cell was equipped with a flat window and argon gas inlet/outlet tubes, which serve to collect and transfer gaseous products to the analytical system. Hydrogen gas evolution was measured by gas chromatography Shimadzu (GC2014) operating with a thermal conductivity detector (TCD) and argon was used as a carrier gas. Aliquots of $1 \mathrm{~mL}$ of the gas phase were injected in the GC system in intervals of $1 \mathrm{~h}$ during five hours of irradiation. In order to ensure the accuracy of the determination and quantification of the hydrogen produced during reaction, a $5 \% \mathrm{H}_{2}$ standard diluted in argon was injected before each experiment. 


\section{Results and Discussion}

The X-ray diffraction patterns for all synthesized samples are shown in Figure 1. The two characteristic peaks of polymeric carbon nitride ${ }^{2,16,17}$ have appeared in all samples. The more intense one is indexed to the diffraction plane (002) and another one with low intensity is indexed to the diffraction plane (100) according to Joint Committee on Powder Diffraction Standards (JCPDS 87-1526). These results indicate that the polymeric structure is formed in all evaluated conditions; however, the diffractograms of the materials synthesized from thiourea (SPCN samples) present more intense peaks than those synthesized from urea (PCN samples), which suggests that thiourea as precursor induces a better crystallinity.

The triazine-based graphitic carbon nitride (TGCN), present in the structure of polymeric carbon nitride, consists of planes with a $\pi$-conjugated system formed by carbon and nitrogen atoms with $\mathrm{sp}^{2}$ hybridization. The interplanar distance in $\mathrm{PCN}$ is approximately $0.327 \mathrm{~nm}$, which is $3 \%$ less than the distance between the graphite planes $(\mathrm{d}=0.335 \mathrm{~nm})$. Such distance decreases due to the higher intensity interaction between the planes because of the presence of nitrogen atoms. ${ }^{18}$ The interplanar (002) distances found for materials synthesized with urea and thiourea as precursors using the Bragg's law are presented in Table 2 alongside all other properties determined in this work.

As can be seen, the PCN lattice parameters are influenced by synthesis conditions, with interplanar distance varying from 0.3254 to $0.3277 \mathrm{~nm}$ for PCN samples and

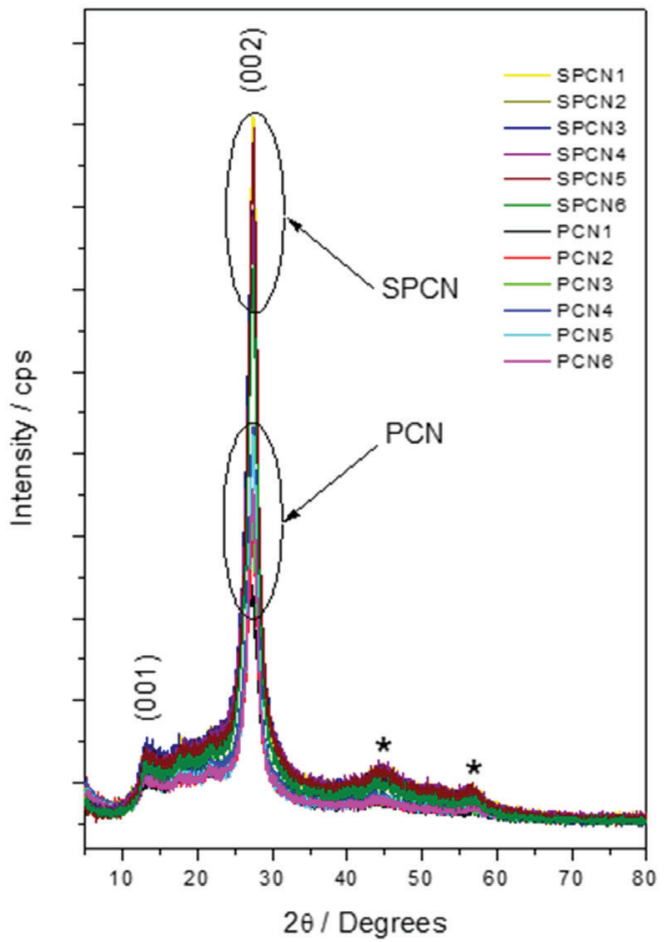

Figure 1. XRD patterns of the powders obtained from different precursors (PCN: urea and SPCN: thiourea) under the thermal treatment conditions described in Table 1. *Polymer melon. ${ }^{16}$

from 0.3251 to $0.3265 \mathrm{~nm}$ for SPCN samples. In general, samples prepared with thiourea had lower interplanar distances, which gives rise in denser structures capable to afford a more efficient electrons mobility throughout the PCN structure.

The crystallite diameters of the samples were estimated with Debye-Scherrer's equation from X-ray diffraction

Table 2. Structural, textural and electronic properties determined for synthesized materials and respective photocatalytic activity

\begin{tabular}{|c|c|c|c|c|c|c|c|c|}
\hline Material & $\mathrm{d}(002) / \mathrm{nm}$ & $\begin{array}{c}\text { S content / } \\
\text { wt. } \%\end{array}$ & $\mathrm{D} / \mathrm{nm}$ & $\begin{array}{c}\text { BET area / } \\
\left(\mathrm{m}^{2} \mathrm{~g}^{-1}\right)\end{array}$ & $\mathrm{Dp} / \mathrm{nm}$ & $\mathrm{Vp} /\left(\mathrm{m}^{3} \mathrm{~g}^{-1}\right)$ & $\mathrm{Eg} / \mathrm{eV}$ & $\begin{array}{c}\mathrm{d}\left[\mathrm{H}_{2}\right] / \mathrm{dt} / \\
\left(\mu \mathrm{mol} \mathrm{g} \mathrm{g}^{-1} \mathrm{~h}^{-1}\right)\end{array}$ \\
\hline PCN1 & 0.3277 & - & 5.95 & 63.25 & 15.87 & 0.25 & 2.75 & 34.35 \\
\hline SPCN1 & 0.3253 & $0.89 \pm 0.04$ & 5.28 & 14.57 & 17.11 & 0.06 & 2.59 & 58.30 \\
\hline PCN2 & 0.3258 & - & 5.71 & 89.44 & 14.12 & 0.32 & 2.66 & 77.75 \\
\hline SPCN2 & 0.3265 & $0.72 \pm 0.07$ & 5.46 & 15.26 & 16.78 & 0.06 & 2.51 & 112.52 \\
\hline PCN3 & 0.3264 & - & 5.03 & 66.61 & 14.73 & 0.25 & 2.70 & 33.22 \\
\hline SPCN3 & 0.3263 & $1.18 \pm 0.05$ & 5.22 & 12.84 & 18.28 & 0.06 & 2.47 & 202.14 \\
\hline PCN4 & 0.3254 & - & 6.28 & 83.40 & 14.16 & 0.30 & 2.76 & 63.00 \\
\hline SPCN4 & 0.3257 & $1.14 \pm 0.10$ & 5.39 & 12.14 & 19.70 & 0.06 & 2.50 & 214.75 \\
\hline PCN5 & 0.3254 & - & 6.92 & 92.07 & 18.95 & 0.44 & 2.74 & 16.54 \\
\hline SPCN5 & 0.3251 & $1.89 \pm 0.12$ & 6.27 & 17.19 & 18.78 & 0.08 & 2.61 & 103.53 \\
\hline PCN6 & 0.3257 & - & 6.22 & 94.39 & 16.06 & 0.40 & 2.78 & 46.00 \\
\hline SPCN6 & 0.3257 & $0.91 \pm 0.10$ & 6.00 & 46.46 & 19.39 & 0.23 & 2.60 & 76.98 \\
\hline
\end{tabular}

d: interplanar distance; D: average diameter of crystallite; BET: Brunauer, Emmett and Teller; Dp: pore diameter; Vp: pore volume; Eg: band gap energy; $\mathrm{d}\left[\mathrm{H}_{2}\right] / \mathrm{dt}$ : hydrogen production rate. 
(XRD) data, using the Bragg diffraction angle at $2 \theta=27.4^{\circ}$. The average diameter of crystallites shown in Table 2 have varied from 5 to $7 \mathrm{~nm}$, indicating all materials are in the size range of nanoparticles.

Sulfur elemental analysis confirms the presence of this element in all samples obtained from thiourea in the range of $0.72-1.89 \%$. For group of samples obtained with $4 \mathrm{~h}$ heat treatment, sulfur incorporation increases with heating rate decrease, reaching the highest S content in the PCN5 sample $(1.89 \%)$, which was obtained at a heating rate of $2{ }^{\circ} \mathrm{C} \mathrm{min}^{-1}$. For samples obtained with a heat treatment time of $6 \mathrm{~h}$, there is no direct relationship between sulfur content and heating rate. In this group of samples, the SPCN4 sample, obtained with intermediary heating rate $\left(5{ }^{\circ} \mathrm{C} \mathrm{min}^{-1}\right)$, presented the highest sulfur incorporation $(1.14 \%)$.

As previously verified in the XRD analyses (Figure 1), the Raman spectra confirm a better crystallinity of the S-doped PCN samples (Figure 2): better spatial order and long-range translation symmetry in the crystal lattice. ${ }^{19,20}$ These properties are reflecting in the sharper and narrower bands than those of the PCN samples that are associated with a better propagation of free charges carriers. Particularly, it is possible to verify the well-defined peak located at $1564 \mathrm{~cm}^{-1}$, identified as $\mathrm{C}=\mathrm{N}$ stretching vibration also defined as $\mathrm{G}$ band, characteristic of the graphitic structure. ${ }^{21-23}$ Such peak is better defined in the samples heated for a longer time. In reference to the heating time, it is possible to see the difference between the sample structures. All the samples heated for $6 \mathrm{~h}$ have shown more crystalline structure and more intense peaks than those heated for only $4 \mathrm{~h}$. In the same way, it is possible to verify that the doped samples heated with a rate of $5^{\circ} \mathrm{C} \mathrm{min}-1$ have a better structure than those others heated at different rates. This can be confirmed with the more

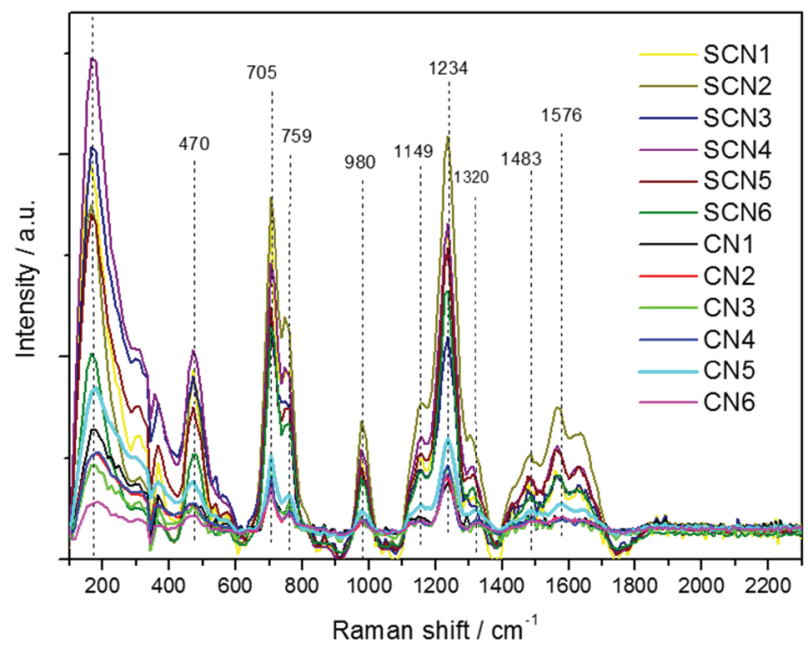

Figure 2. Raman spectra for PCN samples and SPCN samples. intense peaks, particularly near elastic peak (near zero) in the SCN4 spectrum followed by SCN3 in comparison with other samples, which reflects a more "specular" structure in the process of radiation scattering.

All peaks indicated in the Raman spectra belong to PCN and confirm its primitive structure. ${ }^{23,24}$ In particular, the peaks centered at 706 and $980 \mathrm{~cm}^{-1}$ are evidence of a heptazine ring structure. ${ }^{25}$ The first peak is related to in-plane bending vibrations, and the second one can be attributed to the symmetric N-breathing mode of heptazine units. ${ }^{26}$ Several others characteristics peaks are observed in both sample spectra. The peak $470 \mathrm{~cm}^{-1}$ is ascribed to in-plane twisting vibrations of the heptazine heterocycle, while the peak $1234 \mathrm{~cm}^{-1}$ is associated with $=\mathrm{C}\left(\mathrm{sp}^{2}\right)$ bending vibrations. In the same way of the peak $980 \mathrm{~cm}^{-1}$, the lower peak at $1149 \mathrm{~cm}^{-1}$ is A1' vibrations of the tri-striazine ring.

The infrared absorption spectra for all samples have shown a broad band in the range of 3300-3500 $\mathrm{cm}^{-1}$ (Figure 3), characteristic of stretching $\mathrm{N}-\mathrm{H}$ bond of primary and secondary amines. The band associated with $\mathrm{N}-\mathrm{H}$ deformation at $887 \mathrm{~cm}^{-1}$ and the band related to tri$s$-triazine units at $809 \mathrm{~cm}^{-1}$ are also present in all spectra. This set of bands are characteristic of carbon nitride with graphitic structure. ${ }^{12}$ The bands assigned to the stretching of heterocyclic C-N bond ${ }^{12}$ in the range of $1200-1650 \mathrm{~cm}^{-1}$ are also present in infrared spectra of all samples.

The textural properties such as BET area, pore diameter (Dp) and pore volume $(\mathrm{Vp})$ for all samples are displayed in Table 2. One can note that the solids obtained from urea exhibit larger specific surface areas, ranging from 63.25 to $94.39 \mathrm{~m}^{2} \mathrm{~g}^{-1}$, while the solids obtained from thiourea have specific surface areas ranging from 12.14 to $46.46 \mathrm{~m}^{2} \mathrm{~g}^{-1}$ and, in general, smaller pore volumes. In addition to the type of precursor, the heating time also exerts influence on the specific surface area. In general, the larger specific surface areas are associated with longer heating time. On the other hand, there is no significant change in specific surface area with heating rates of 5 and $10{ }^{\circ} \mathrm{C} \mathrm{min}{ }^{-1}$, but when the rate is $2{ }^{\circ} \mathrm{C} \mathrm{min}-1$ a significant increase in specific surface area is observed, mainly for materials obtained from urea. All samples had a pore diameter between 2 and $50 \mathrm{~nm}$, which is characteristic of mesoporous material. However, the pore diameters of the solids obtained from urea are smaller than those of the solids obtained from thiourea are.

SEM images are shown in Figure 4. All the samples display aggregated morphologies, which consist of smaller particles. The micrographs profile suggests the presence of lamellar structure with surface peeling where is more evident in SPCN samples. 

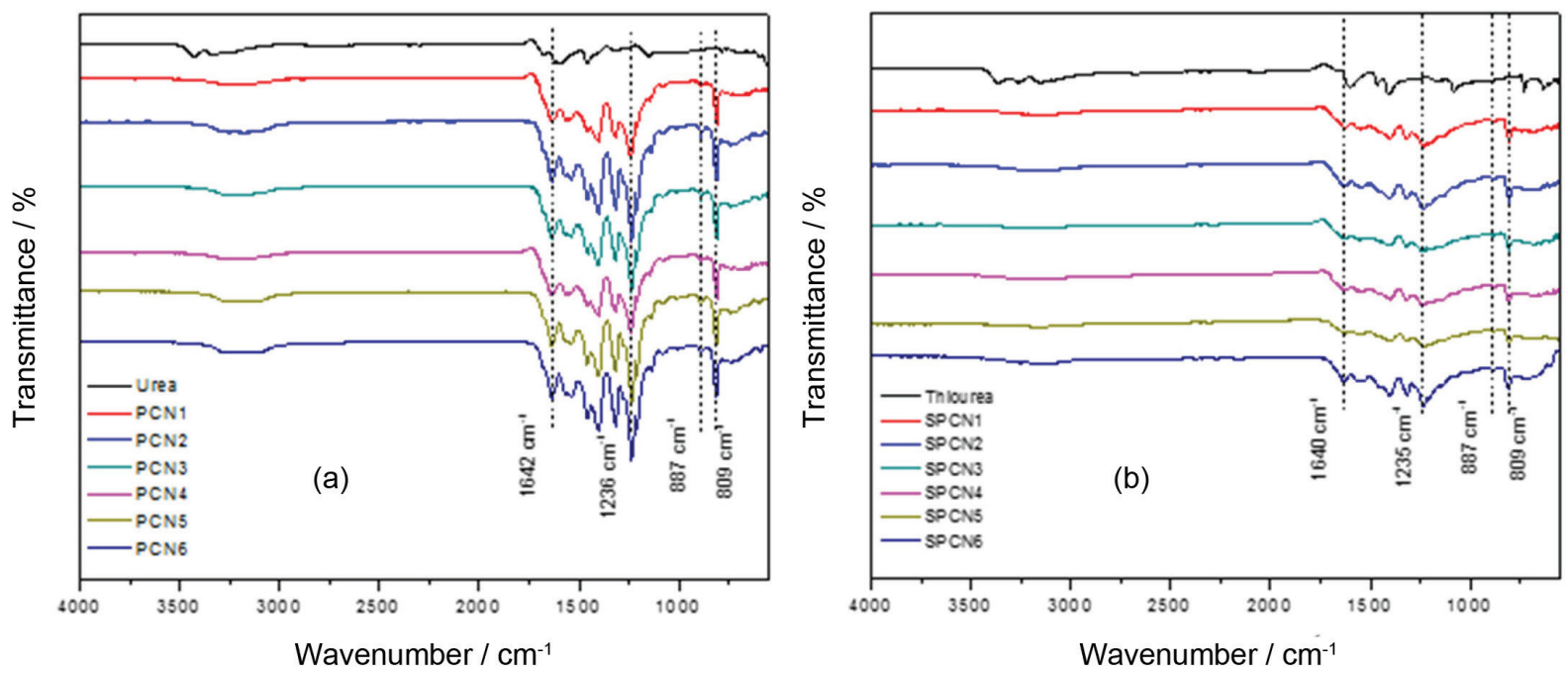

Figure 3. ATR-FTIR absorption spectra for PCN samples (a) and SPCN samples (b) and their respective precursors.

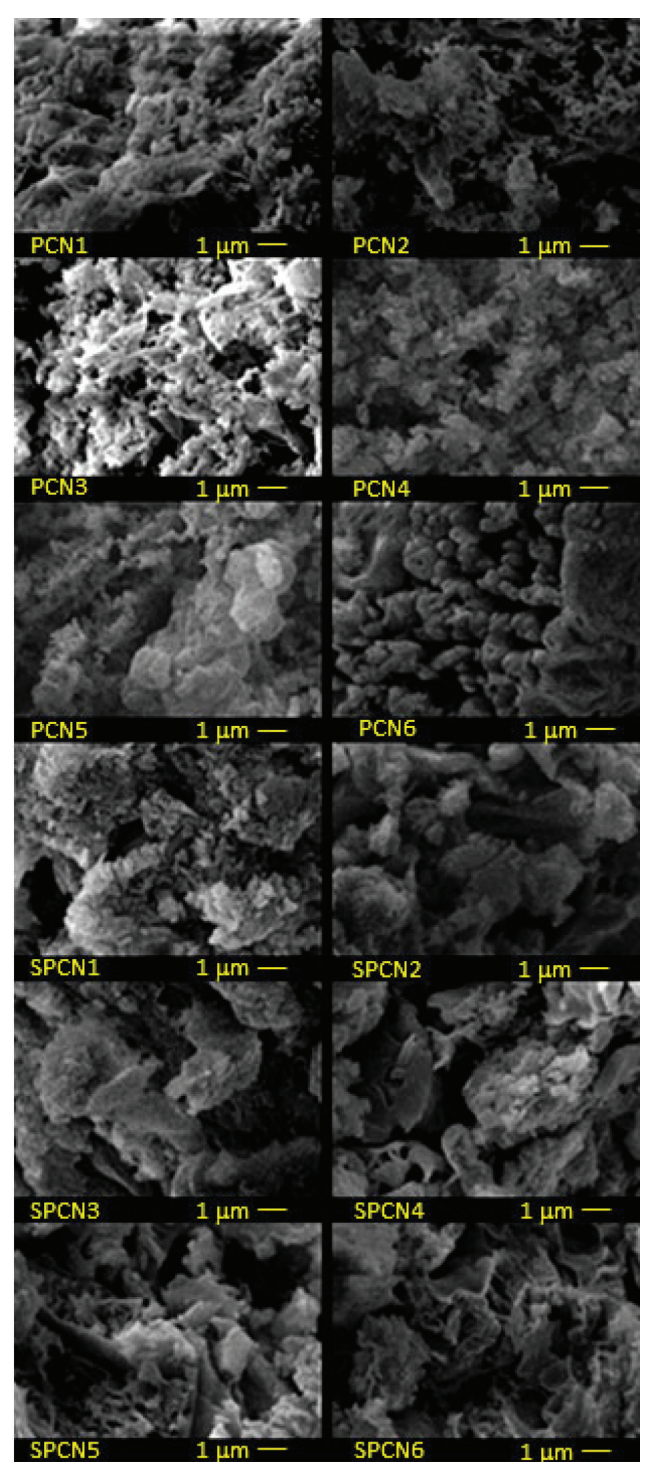

Figure 4. SEM images for PCN samples and SPCN samples showing the different morphologies.
The diffuse reflectance spectra of the samples indicate an extending photosensitivity for materials obtained from thiourea in comparison with materials obtained from urea (Figures $5 \mathrm{a}$ and $5 \mathrm{~b}$ ) due to sulfur doping that increases the absorbance toward the visible light region. The optical band gap energies (Eg) depicted in Table 2 were obtained applying the geometrical method to the diffuse reflectance spectroscopy (DRS) experimental data, assuming direct band transitions, which uses the relation in equation $1 .^{27}$

$\mathrm{Ih} v=\mathrm{A}(\mathrm{h} v-\mathrm{Eg})^{1 / 2}$

where I is the absorption intensity, A is a coefficient, and $\mathrm{h} v$ is the photon energy. Eg values were obtained by the extrapolation of the best-fit line between (Ihv) ${ }^{2}$ and hv up to the point where it crosses the ordinate axis, as illustrated in Figure 5c. The band gap energies for samples obtained from urea range from 2.66 to $2.78 \mathrm{eV}$, very close to $\mathrm{Eg}$ for pure $\mathrm{PCN}(\mathrm{Eg}=2.7 \mathrm{eV}) ;{ }^{28}$ while the samples obtained from thiourea have narrower band gap energies in the range from 2.47 to $2.61 \mathrm{eV}$. The energy levels of sulfur-doped PCN are affected by the insertion of higher energy orbitals (3p) in the valence band as well by the smaller distance between $\pi$-conjugation planes (d) observed in the XRD analysis (Table 2), which results in the band gap narrowing.

All samples were evaluated as photocatalysts in hydrogen production reaction. The hydrogen production rate was measured from an aqueous solution containing EDTA as a hole scavenger and platinum as a cocatalyst under visible light irradiation ( $\lambda \geq 420 \mathrm{~nm}$ ) for five hours (results are shown in Table 2). A blank reaction at the same conditions without photocatalyst was also performed and no hydrogen was detected during five hours irradiation. Among the solids obtained from urea, samples PCN2, PCN4 and 

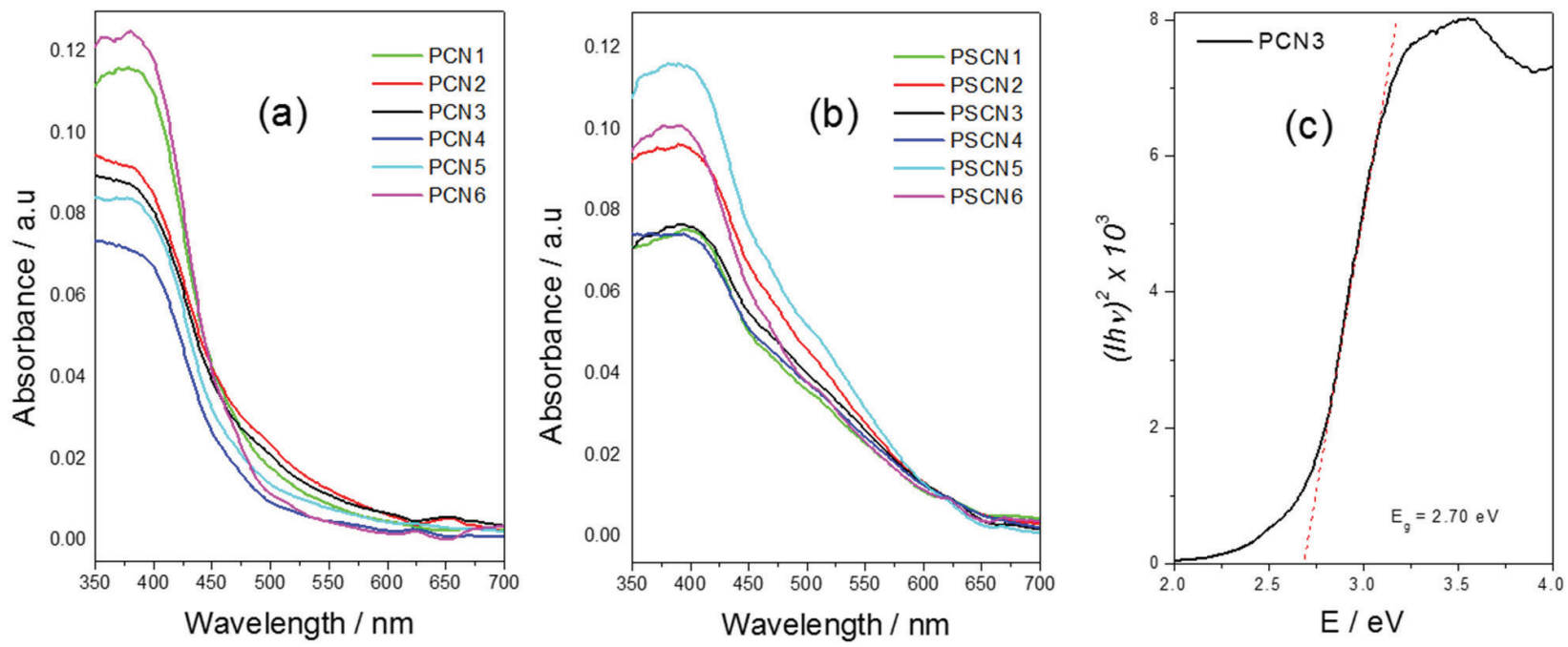

Figure 5. Diffuse reflectance spectra for PCN samples (a), SPCN samples (b) and a graphical example for determining Eg (c).

PCN6 were the ones with the highest hydrogen production rate, 77.75, 63.00 and $46.00 \mu \mathrm{mol} \mathrm{g} \mathrm{g}^{-1} \mathrm{~h}^{-1}$ respectively. These results indicate that for PCN samples the longest heating time $(6 \mathrm{~h})$ improves the photocatalytic properties of PCN, which implies in higher crystallinity. However, the photoactivity decreases as heating rate decreases, reaching the best activity with the photocatalyst obtained with heating rate at $10{ }^{\circ} \mathrm{C} \mathrm{min}^{-1}$. In all cases, photocatalysts obtained from thiourea are more active than when prepared from urea under the same synthesis conditions. The more active SPCN samples were SPCN3 and SPCN4, which yielded hydrogen production rates of 202.14 and $214.75 \mu \mathrm{mol} \mathrm{g}^{-1} \mathrm{~h}^{-1}$, respectively. In this way, it is possible to associate the best photocatalytic activity to the band gap narrowing, due to the presence of sulfur as a heteroatom. In addition, the intermediary heating rate $\left(5^{\circ} \mathrm{C} \mathrm{min}^{-1}\right)$ and longer heat treatment time $(6 \mathrm{~h})$ result in crystalline material with less structural disorders, as predicted by the Raman measures. Although it results in a lower surface area, the combination of these two factors decreases the defects in the solid, which contributes to improve the photoacatalytic activity, since defects are points of charges recombination. ${ }^{25,29}$

The fluorescence signal intensity in solids is assigned to recombination of photogenerated electron-hole pairs..$^{30,31}$ In this sense, photoluminescence (PL) emission spectrum is a valuable tool to assess the recombination process of photogenerated charges carrier that occurs in illuminated photocatalysts, since a high PL signal is associated with a high rate of charges carrier recombination. ${ }^{32}$ In the same way, part of the photogenerated electron-hole pairs can promote reduction and oxidation of adsorbed species, improving the photocatalytic activity. In order to evaluate the process of charges recombination as well as photocatalytic activity in the irradiated photocatalysts, we performed photoluminescence measurements and the recorded PL spectra, not normalized, for all synthesized samples are shown in Figure 6.

A multi-peak fitting of the PL spectra (illustrated for PCN4 sample) has identified the three characteristic bands of $\mathrm{g}-\mathrm{C}_{3} \mathrm{~N}_{4}$ assigned to the transitions $\pi^{*}-\pi, \sigma^{*}$-lone pair and $\pi^{*}$-lone pair. ${ }^{33-35}$ The three transition bands are present in the spectra of all samples, but less intense in SPCN

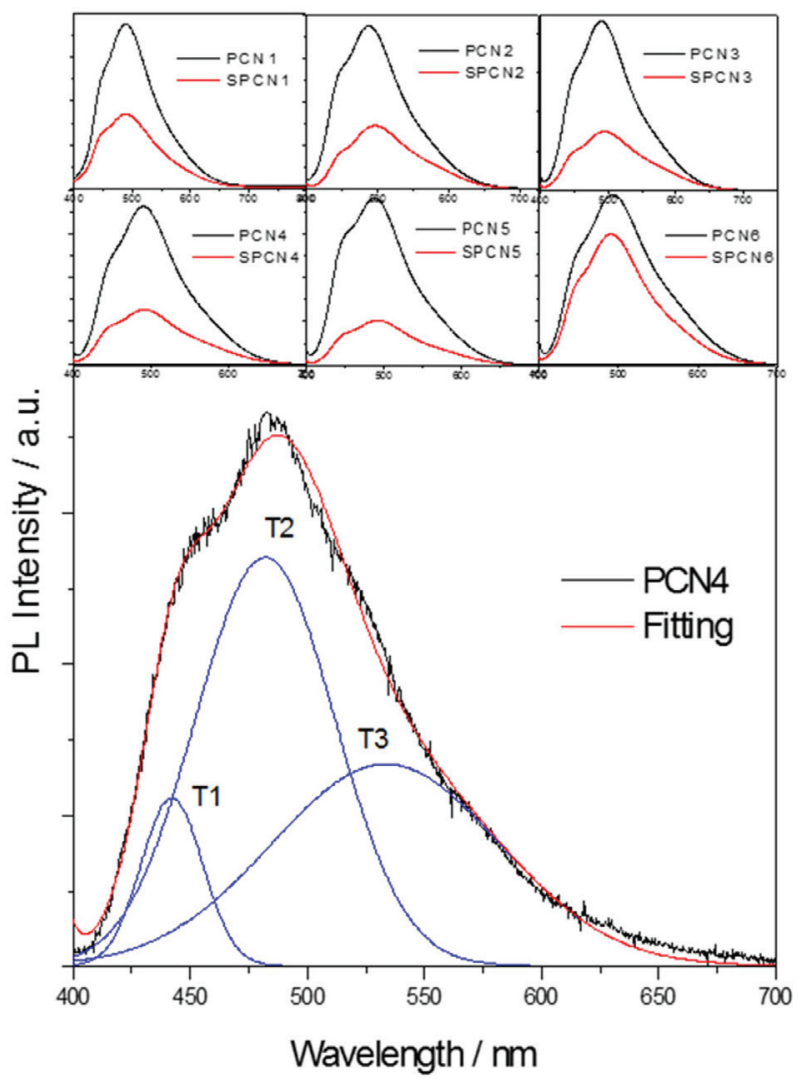

Figure 6. Photoluminescence spectra for PCN and SPCN samples (on top) and Gaussian peaks fitting of the PCN4 (below) PL emission spectra. 
samples. Therefore, the decrease in photoluminescence intensity of SPCN samples when compared to PCN samples indicates a suppression of charge recombination. This fact associated with the low structural disorder, corroborated by X-ray diffraction and Raman spectroscopy, justify the improvement of photocatalytic activity for S-doped PCN samples, especially for the SPCN4 sample that presented the best photocatalytic performance. Besides this, when we compare the samples heated at different times, it is possible to verify a slight red shift for all samples heated for $6 \mathrm{~h}$, indicating that the PL spectrum is not so affected by these heating times..$^{34,35}$

\section{Conclusions}

The synthesis parameters for PCN preparation by thermal polycondensation strongly influence on photoactivity to produce hydrogen. The band gap narrowing with the use of thiourea as a precursor, as well as the use of an intermediate heating rate $\left(5^{\circ} \mathrm{C} \mathrm{min}^{-1}\right)$ and a longer thermal treatment time $(6 \mathrm{~h})$ resulted in a solid with best crystallinity that contributes to decrease the process of charge recombination. All characterizations have shown that the combination of these effects led the SPCN4 sample to the highest photocatalytic activity, yielding a hydrogen production rate of $214.75 \mu \mathrm{mol} \mathrm{g}^{-1} \mathrm{~h}^{-1}$.

\section{Acknowledgments}

The authors acknowledge the Brazilian research funding agencies Conselho Nacional de Desenvolvimento Científico e Tecnológico (CNPq) for D. S. Monteiro fellowship and Fundação de Amparo à Pesquisa do Estado da Bahia (FAPESB)-grant code APP0050/2016. The authors are also thankful to Laboratório Multi-Usuário de Microscopia Eletrônica da UFBA (LAMUME) for the SEM analyses, Centro de Laser da Faculdade de Odontologia da UFBA for Raman analysis and Prof Vanessa Hatje and Rodrigo Aguiar for sulfur analysis.

\section{References}

1. Chen, Z.; Savateev, A.; Pronkin, S.; Papaefthimiou, V.; Wolff, C.; Willinger, M. G.; Willinger, E.; Neher, D.; Antonietti, M.; Dontsova, D.; Adv. Mater. 2017, 29, 1700555.

2. Teixeira, I. F.; Barbosa, E. C. M.; Tsang, S. C. E.; Camargo, P. H. C.; Chem. Soc. Rev. 2018, 47, 7783.

3. Zhang, G.; Zhang, J.; Zhang, M.; Wang, X.; J. Mater. Chem. 2012, 22, 8083 .

4. Thomas, A.; Fischer, A.; Goettmann, F.; Antonietti, M.; Muller, J.; Schlogl, R.; Carlsson, J.; J. Mater. Chem. 2008, 18, 4893.
5. Jiang, Y.; Sun, Z.; Tang, C.; Zhou, Y.; Zeng, L.; Huang, L.; Appl. Catal., B 2019, 240, 30.

6. Liu, J.; Fang, W.; Wei, Z.; Qin, Z.; Jiang, Z.; Shangguan, W.; Appl. Catal., B 2018, 238, 465.

7. Li, H.; Li, F.; Wang, Z.; Jiao, Y.; Liu, Y.; Wang, P.; Zhang, X.; Qin, X.; Dai, Y.; Huang, B.; Appl. Catal., B 2018, 229, 114.

8. Wu, X.; Chen, F.; Wang, X.; Yu, H.; Appl. Surf. Sci. 2018, 427, 645.

9. Oh, T. H.; Energy 2016, 112, 679.

10. Cao, L.; Wang, R.; Wang, D.; Mater. Lett. 2015, 149, 50.

11. Lin, Q.; Li, L.; Liang, S.; Liu, M.; Bi, J.; Wu, L.; Appl. Catal., B 2015, 163, 135.

12. Zhu, B.; Xia, P.; Ho, W.; Yu, J.; Appl. Surf. Sci. 2015, 344, 188.

13. Ge, L.; Han, C.; Xiao, X.; Guo, L.; Int. J. Hydrogen Energy 2013, 38, 6960.

14. Yuan, Y-P.; Xu, W-T.; Yin, L-S.; Cao, S-W.; Liao, Y-S.; Tng, Y-Q.; Xue, C.; Int. J. Hydrogen Energy 2013, 38, 13159.

15. Dong, G.; Zhang, Y.; Pan, Q.; Qiu, J.; J. Photochem. Photobiol., C 2014, 20, 33.

16. Fina, F.; Callear, S. K.; Carins, G. M.; Irvine, J. T. S.; Chem. Mater. 2015, 27, 2612.

17. Tyborskil, T.; Merschjann, C.; Orthmann, S.; J. Phys.: Condens. Matter 2013, 25, 1.

18. Zhu, J.; Xiao, P.; Li, H.; ACS Appl. Mater. Interfaces 2014, 6, 16449.

19. Tilley, R. S.; Crystals and Crystal Structures, $1^{\text {st }}$ ed.; Wiley: Chichester, UK, 2007.

20. Sherwood, P. M. A.; Vibrational Spectroscopy of Solids, $2^{\text {nd }}$ ed.; Cambridge University Press: London, UK, 1972, p. 4.

21. Abdoul-Carime, H.; Bald, I.; Illenberger, E.; Kopyra, J.; J. Phys. Chem. C 2018, 122, 25183.

22. Rodil, S. E.; Ferrari, A. C.; Robertson, J.; Muhl, S.; Thin Solid Films 2002, 420-421, 122.

23. Jiang, J.; Ou-yang, L.; Zhu, L.; Zheng, A.; Zou, J.; Yi, X.; Tang, H.; Carbon 2014, 80, 213.

24. Jourshabani, M.; Shariatinia, Z.; Badiei, A.; J. Mol. Liq. 2017, 248,688

25. Tonda, S.; Kumar, S.; Kandula, S.; Shanker, V.; J. Mater. Chem. A 2014, $2,6772$.

26. Zheng, Y.; Yu, Z.; Lin, F.; Guo, F.; Alamry, K. A.; Taib, L. A.; Asiri, A. M.; Wang, X.; Molecules 2017, 22, 572.

27. Ferreira da Silva, A.; Veissid, N.; An, C. Y.; Pepe, I.; de Oliveira, N. B.; Batista da Silva, A. V.; Appl. Phys. Lett. 1996, 69, 1930.

28. Mamba, G.; Mishra, A. K.; Appl. Catal., B 2016, 198, 347.

29. Qian, R.; Zong, H.; Schneiderc, J.; Zhou, G.; Zhao, T.; Li, Y.; Yang, J.; Bahnemann, D. W.; Pan, J. H.; Catal. Today 2019, $335,78$.

30. Huang, Z. F.; Song, J.; Pan, L.; Wang, Z.; Zhang, X. Q.; Zou, J.; Mi, W.; Zhang, X. W.; Wang, L.; Nano Energy 2015, 12, 646. 
31. Stolbov, S.; Zuluaga, S.; J. Phys.: Condens. Matter 2013, 25, 085507.

32. Ge, L.; Han, C.; Xiao, X.; Guo, L.; Li, Y.; Mater. Res. Bull. 2013, 48, 3919.

33. Yuan, Y.; Zhang, L.; Xing, J.; Utama, M. I. B.; Lu, X.; Du, K.; Li, Y.; Hu, X.; Wang, S.; Genç, A.; Dunin-Borkowski, R.; Arbiold, J.; Xiong, Q.; Nanoscale 2015, 7, 12343.
34. Zhang, Y.; Pan, Q.; Chai, G.; Liang, M.; Dong, G.; Zhang, Q.; Qiu, J.; Sci. Rep. 2013, 3, 1943.

35. Wang, B. B.; Cheng, Q. J.; Wang, L. H.; Zheng, K.; Ostrikov, K.; Carbon 2012, 50, 3561.

Submitted: August 6, 2019 Published online: October 29, 2019 